\title{
Movement recognition and preference in home-based robot-assisted stroke rehabilitation
}

\author{
Angelo Basteris \\ University of Hertfordshire \\ College Lane \\ AL10 9AB Hatfield - UK \\ +441707284630 \\ angelobasteris@gmail.com
}

\author{
Farshid Amirabdollahian \\ University of Hertfordshire \\ College Lane \\ AL10 9AB Hatfield - UK
}

\section{f.amirabdollahian2@herts.ac.uk}

\begin{abstract}
Robots can be effective tools for rehabilitation of subjects with stroke. Furthermore, home-based robotic rehabilitation could reduce the costs and improve the therapy outcome. We worked on such a context within the SCRIPT (Supervised Care and Rehabilitation Involving Personal Telerobotics) project. We designed a system composed of a wearable passive orthosis which assists and measures hand and wrist movements, a personal computer and motivational and interactive games. In this paper, we focused on the definition of the movements which are used to play the interactive games. We considered the results of testing our methods on 20 subjects with chronic stroke who completed a six weeks clinical trial and investigated their preference of certain movements. Our results show a tendency to train hand movements among subjects with lower impairment and wrist movements for more impaired participants.
\end{abstract}

\section{General Terms}

Performance, Experimentation,

\section{Keywords}

Robot, stroke, home, rehabilitation, interactive games

\section{INTRODUCTION}

\subsection{Background}

Majority of literature show that, after the event of a stroke, patients have at least 12 months during which their brains are highly susceptible to the benefits of neuro-rehabilitation [11]. On the other hand, due to the high costs of clinical neuro-rehabilitation, post-stroke treatments are limited in most countries to only a few weeks after the stroke event. Hence, any system aimed at prolonging neuro-rehabilitation out of the clinics, i.e. at patients' homes, and with low costs treatments, provides a chance to exploit potential recovery towards better life quality and a more independent individual thus addressing one of the major challenges of in the current health systems.

Permission to make digital or hard copies of all or part of this work for personal or classroom use is granted without fee provided that copies are not made or distributed for profit or commercial advantage and that copies bear this notice and the full citation on the first page. To copy otherwise, to republish, to post on servers or to redistribute to lists, requires prior specific permission and/or a fee. REHAB 2014, May 20-23, Oldenburg, Germany Copyright (C) 2014 ICST 978-1-63190-011-2

DOI 10.4108/icst.pervasivehealth.2014.255314

\subsection{Robot-assisted rehabilitation}

The earlier studies on robot-assisted rehabilitation targeted training for reaching to targets, due to the inherent complexity of designing grasping tools. However, hand and wrist function have a more pronounced impact on individual's independence and performance in activities of daily living. In line with this, a smaller and more recent subset has targeted training of the hand and wrist. In most cases, focus was specifically on training of either wrist $[5,6,9]$ or hand $[7,12]$, inherently from the design of the device. A smaller number of systems integrate training of arm, wrist and hand functions [4, 10]. However, it is still unclear whether focusing the training on arm, wrist or hand functions leads to benefits in therapy outcome.

\subsection{About SCRIPT}

One of the main objectives of SCRIPT project is the user-driven technology development for stroke rehabilitation at home. This includes designing a passive-actuated hand and wrist therapy device and also designing a motivating and engaging front end i.e. interactive games for the user, with a particular focus on usability. An underlying component which connects the orthosis and the front-end makes the human-robot interaction therapeutic

Our approach for developing such component was that of defining a gesture recognition system which enabled subjects to control the games by moving their arm, wrist and fingers. This modular approach makes such interaction potentially expandable to other games and allows a more comprehensive training. Design and development was evaluated using formative assessment of the work with a triad of patients, their family members and their health care professionals. The system had then undergone summative evaluation with 20 patients. In this paper, we investigate how subjects focused on arm, wrist or hand training, based on their level of impairment.

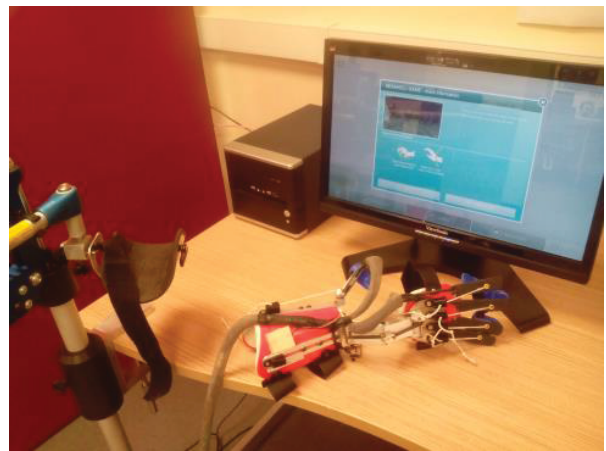

Figure 1 The SCRIPT system.Videos demonstrating the system can be found on the Youtube channel http://g00.gl/fpaZUD 


\section{METHODS}

\subsection{The SCRIPT passive orthosis}

The SCRIPT passive orthosis [1] is an exoskeleton which assists subjects in finger and wrist extension by providing an offset torque by means of elastic elements. It also features several sensors. Each finger flexion is measured by a resistive sensor, a potentiometer measures the wrist angle and an inertial measurement unit which provides information about velocity and orientation of the hand.

\subsection{Arm model}

The data from the device are sampled at $30 \mathrm{~Hz}$ and used as input to a Python 21 DOF (four for each finger - three for the thumb, flexion/extension and lateral abduction/adduction of the wrist). We start with the hand in neutral position (flat, with no wrist flexion/extension). The first step consists of modifying the three values of flexion per finger, based on the flexion sensors readings, which results as the sum of metacarpal, proximal and distal interphalangeal joints flexion angles. We partition such value over the joints by multiplying it by a constant vector. Lateral abduction/adduction of fingers is not measured by the device, thus held constant in the model. The model also includes a single parameter to measure the opening of the hand, handOpening. We considered the fingertips to be closer to each other with a closed hand than with an open hand. Let $F n$ be the three dimensional array representing the fingertips positions for the $n$-th finger. Then if $F_{X}, F_{Y}$ and $F z$ are the arrays containing the $\mathrm{x}, \mathrm{y}$ and $\mathrm{z}$ coordinates of all the five fingers, then $D=\left\|\operatorname{std}\left(\mathrm{F}_{X}\right) \operatorname{std}\left(\mathrm{F}_{Z}\right) \operatorname{std}\left(\mathrm{F}_{Z}\right)\right\|$, is proportional to the distance among the fingers and thus to hand opening. We normalized such value in a range obtained $[0,1]$ with respect to the values measured when all fingers were flexed and extended, respectively.

Moreover, measured rotation from the IMU handRoll is applied to the hand. Finally, the wrist flexion angle wrist $Q$ is set in the model. The hand position is held constant, as the IMU measured its velocity, of which we considered components on the IMU plane wrist $X^{\prime}$ and wrist $Y^{\prime}$ only. Such information is held out of the model, but is used for some gestures within the games.

\subsection{Gestures definitions}

Activities of daily living include eating with a knife and fork, drinking, holding objects, keyboard work, taking money from purse, buttoning a shirt, combing hair and door handle manipulation.

All of these require several movements of hand and wrist. It is elemental that retraining of hand and wrist movements should

Table 1 Specifications of the gestures recognized. Different color shadings highlight movements of hand, wrist and arm.

\begin{tabular}{llll}
\hline $\begin{array}{l}\text { Gesture } \\
\text { related quantity }\end{array}$ & Specification & \\
\hline $\begin{array}{l}\text { Hand open } \\
\text { handOpening }\end{array}$ & $\begin{array}{l}\text { Combined information from finger } \\
\text { sensors is in a range }(90-100 \%)\end{array}$ \\
$\begin{array}{l}\text { Hand close } \\
\text { handOpening }\end{array}$ & $\begin{array}{l}\text { Combined information from finger } \\
\text { sensors is in a range(0-10\%) }\end{array}$ \\
$\begin{array}{l}\text { Grasping } \\
\text { handOpening }\end{array}$ & $\begin{array}{l}\text { Combined information from finger } \\
\text { sensors is in a range (40-70\% of } \\
\text { maximum value) }\end{array}$ \\
\hline
\end{tabular}

\begin{tabular}{|c|c|}
\hline $\begin{array}{ll}\text { Wrist } & \text { flexed } \\
\text { wristQ } & \end{array}$ & $\begin{array}{l}\text { Angle from wrist sensor is in a range } \\
\text { around t its upper boundary }(90-100 \%)\end{array}$ \\
\hline $\begin{array}{l}\text { Wrist } \\
\text { extended } \\
\text { wristQ }\end{array}$ & $\begin{array}{l}\text { Angle from wrist sensor is in a range } \\
\text { around t its lower boundary }(0-10 \%)\end{array}$ \\
\hline $\begin{array}{l}\text { Hand prone } \\
\text { handRoll }\end{array}$ & Hand roll angle is in a range $(90-100 \%)$ \\
\hline $\begin{array}{l}\text { Hand supine } \\
\text { handRoll }\end{array}$ & Hand roll angle is in a range $(0-10 \%)$ \\
\hline $\begin{array}{l}\text { Hand Forward } \\
\text { wristY' }\end{array}$ & $\begin{array}{l}\text { Hand anteroposterior velocity is around } \\
\text { its upper boundary }(80-100 \%)\end{array}$ \\
\hline $\begin{array}{l}\text { Hand } \\
\text { Backward } \\
\text { wristY' }\end{array}$ & $\begin{array}{l}\text { Hand anteroposterior velocity is around } t \\
\text { its lower boundary (0-20\%) }\end{array}$ \\
\hline $\begin{array}{l}\text { Hand } \\
\text { wristX' }\end{array}$ & $\begin{array}{l}\text { Hand horizontal velocity is in a range (80- } \\
100 \%)\end{array}$ \\
\hline $\begin{array}{l}\text { Hand } \\
\text { wrist } X^{\prime}\end{array}$ & $\begin{array}{l}\text { Hand lateral velocity has gone in a range } \\
(80-100 \%)\end{array}$ \\
\hline
\end{tabular}

include some of the basic components of these gestures. Thus, the device intervenes on flexion/extension movement of both wrist and fingers.

Thus, we first focused on identifying whether the subject had reached a full flexed or extended wrist position or his/her hand is being fully opened or fully closed, respectively. However, training should include movements similar to those performed during ADL. We hence identified a list of gestures, of which a subset is used in a specific game/category. Table 1 lists the gestures recognized by the training system and their specifications. If a gestures was performed, it was required that the condition which determined its recognition became false before this gesture could be recognized again. As a consequence of this, if for example one opened the hand and held it open only one "Hand Open"gesture would have been recognized no matter how long the hand was held open.

For each session, the reference values were measured for each of the required gestures by a calibration algorithm which we described in previous work $[2,3]$.

\subsection{Games}

These gestures are matched with actions within the games that are intended for providing motivating exercise. Three games were available: "Sea Shell", "Super Crocco" and "Labyrinth". In the Sea Shell game, the patient operates a shell using his/her hand in order to catch fishes. In the Super Crocco game, in addition to grasping, wrist flexion and extension are performed to avoid obstacles, and lateral movements of the hand to move the character on the screen. The Labyrinth game offers, in addition to this, training of forearm prone/supination and antero-posterior movements of the hand.

\subsection{Experimental protocol}

Twenty chronic stroke subjects from three countries (Netherlands, Italy and United Kingdom) completed six weeks of training as part of an ongoing clinical trial [8]. Subjects received arm and hand training at home using the SCRIPT system. All subjects trained independently, and were remotely supervised, off-line, by a healthcare professional (HCP). Subjects were recommended to 
train 180 minutes per week but they were free to choose their own preferred training time and exercise. During the first training week, the HCP visited each subject three times, in order to ensure competence with the SCRIPT system. During the other training weeks, the HCP visited each subject once per week to check on the subject's performance. Subjects were assessed by Fugl-Meyer (FM) in the week before the intervention.

\subsection{Data analysis}

We considered as indicator of the efficacy of gesture recognition the total number of movements recognized and its distribution among different gestures, for each subject. We investigated whether difference in gestures frequencies exist between subjects with different level of impairment by correlating the frequency of hand (sum of the frequency of Hand Open, Grasping and Hand Close), wrist (sum of Wrist Flexed and Extended movements) and arm(Hand Left, Right, Forward or Backward) with FM at inclusion.

\section{RESULTS}

\subsection{Overall number of gestures}

Overall, subjects performed 587 sessions, for a total of 542373 gestures recognized.

Figure 1 shows the frequency of each gesture, by showing the mean value among all subjects. Generally, participants showed the tendency to train hand movements (in green), rather than wrist ones (in blue). The lower recurrence of gross arm movements is reflective of the requirements of the games, which focused mainly on either wrist or hand movements and eventually included also arm movements.

\subsection{Differences among subjects in number of gestures}

Despite this overall tendency, we observed remarkable differences among subjects in the distribution of hand, wrist and arm movements.

Table 2 shows characteristics and results (frequency of different gestures and therapeutic outcome) for each subject.

It is noteworthy that, given the opportunity to choose training times and intensity and duration on their own, subjects exhibit a very high variability in amount of training, with number of gestures detected by the system ranging from 4173 to 91493 between subjects.

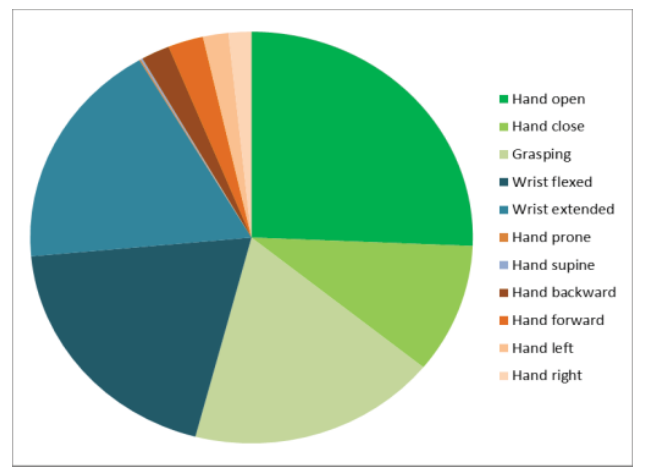

Figure 1 Mean frequency of each of the 11 gestures, all subjects. Movements of the hand were preferred over wrist and arm movements. Green shades represent hand movements, blue shades represent wrist movements and orange shades represent arm movements.

Table 2 Subjects characteristics and baseline scores, number of movements performed and gains in clinical scores. Subjects are presented in order of increasing FM score before therapy.

\begin{tabular}{|ccc|c|cccc|}
\hline Id & $\begin{array}{c}\text { Gende } \\
\text { r }\end{array}$ & Age & $\begin{array}{c}\text { FM } \\
\text { at } \\
\text { inclusio } \\
\text { n }\end{array}$ & $\begin{array}{c}\text { Number } \\
\text { of } \\
\text { gestures }\end{array}$ & $\begin{array}{c}\text { Hand } \\
\text { \% }\end{array}$ & $\begin{array}{c}\text { Wrist } \\
\text { \% }\end{array}$ & $\begin{array}{c}\text { Arm } \\
\text { \% }\end{array}$ \\
\hline n10 & F & 61 & 9 & 36320 & 1 & 98 & 1 \\
\hline n10 & M & 43 & 11 & 70925 & 12 & 87 & 0 \\
\hline n10 & M & 62 & 12 & 7324 & 34 & 61 & 5 \\
\hline en1 & F & 79 & 16 & 9687 & 9 & 75 & 16 \\
\hline it02 & M & 62 & 16 & 25052 & 89 & 10 & 1 \\
\hline n10 & M & 52 & 17 & 6320 & 60 & 38 & 1 \\
\hline it08 & F & 56 & 31 & 16255 & 73 & 18 & 9 \\
\hline it12 & M & 80 & 31 & 46580 & 61 & 31 & 8 \\
\hline it04 & F & 73 & 34 & 27231 & 58 & 35 & 7 \\
\hline it05 & F & 65 & 37 & 5744 & 86 & 14 & 0 \\
\hline it11 & F & 62 & 38 & 5846 & 66 & 21 & 13 \\
\hline en0 & F & 43 & 42 & 38334 & 80 & 13 & 7 \\
\hline n10 & M & 58 & 44 & 4173 & 53 & 41 & 6 \\
\hline en1 & F & 63 & 45 & 83170 & 46 & 49 & 5 \\
\hline it06 & F & 66 & 46 & 12151 & 21 & 32 & 46 \\
\hline n10 & F & 68 & 46 & 2377 & 59 & 38 & 3 \\
\hline n10 & M & 69 & 49 & 19061 & 54 & 41 & 5 \\
\hline it10 & M & 35 & 50 & 23187 & 65 & 21 & 14 \\
\hline n11 & M & 58 & 53 & 91493 & 94 & 5 & 1 \\
\hline n10 & M & 34 & 56 & 11143 & 61 & 24 & 15 \\
\hline
\end{tabular}

Table 3 shows the correlation between frequencies of hand and wrist movements with FM scores at inclusion. The positive correlation coefficients of frequency of the movement of the hand - and negative for movements of the wrist - indicates that more impaired subjects tended to focus on wrist movements, while subjects with milder impairment trained on hand movement.

Table 3 Correlation between frequency of hand and wrist movements with Fugl-Meyer at inclusion

\begin{tabular}{|c|c|c|}
\hline \multicolumn{2}{|c|}{} & $\begin{array}{c}\text { FM at } \\
\text { inclusion }\end{array}$ \\
\hline \multirow{3}{*}{ HAND } & $\begin{array}{c}\text { Pearson } \\
\text { Correlation }\end{array}$ & $.481^{*}$ \\
\cline { 2 - 3 } & Sig. (2-tailed) & .032 \\
\hline \multirow{2}{*}{ WRIST } & $\begin{array}{c}\text { Pearson } \\
\text { Correlation }\end{array}$ & $-.629^{* *}$ \\
\cline { 2 - 3 } & $\begin{array}{c}\text { Sig. (2-tailed) } \\
\text { ARM }\end{array}$ & $\begin{array}{c}\text { Pearson } \\
\text { Correlation }\end{array}$ \\
\cline { 2 - 3 } & Sig. (2-tailed) & .339 \\
\hline \multirow{2}{*}{} & .144 \\
\hline
\end{tabular}




\section{CONCLUSIONS AND FUTURE WORK}

We designed a system able to detect movements of arm, wrist and hand, and allow subjects with stroke to control interactive games. The system was evaluated for feasibility for home-use by stroke patients, over a period of 6 weeks. Our results indicate that subjects differed in training, with subjects with higher level of impairment focusing on wrist movements while subjects with milder impairment were more keen on training hand functions.

A natural follow-up question is whether these repetitive trainings resulted in any significant clinical changes as reflected by the FM test. This is the subject of our ongoing investigation in the project.

Future work comprehends the enhancement of gross arm movements detection by means of optical tracking and the recognition of new, more functional types of hand postures incorporated into 6 new games. This will allow identifying whether the clustering effect observed here was due to the small number of games available or whether this is indeed a preference effect resulting from patient's level of impairment. Furthermore, we will consider cases where significant clinical changes were identified and observe whether these comply with the preference, or whether when patients try games that are not preferred, a more significant clinical change can be achieved.

\section{ACKNOWLEDGMENTS}

This work has been partially funded under Grant FP7-ICT-288698 (SCRIPT) of the European Community Seventh Framework Programme.

We are grateful to the SCRIPT consortium for the design and implementation of the system and clinical study. We are also grateful to the patients who participated in the study and hence provided the data for this paper.

\section{REFERENCES}

1. Ates, S.L., P. ; van der Kooij, H.;Stienen, A.H. SCRIPT Passive Orthosis: Design and Technical Evaluation of the Wrist and Hand Orthosis for Rehabilitation Training at Home in International Conference on Rehabilitation Robotics (ICORR), Seattle, USA, 2013.

2. Basteris, A. and Amirabdollahian, F. Adaptive humanrobot interaction based on lag-lead modelling for home-based stroke rehabilitation in IEEE Systems, Man and Cybernetics, Manchester (UK), 2013.

3. Basteris, A.Rahman, N.; Amirabdollahian,F., Rapid assessment of range of motion and movement duration during human-robot interaction. in World Congress on NeuroRehabilitation, Istanbul (Turkey), 2014.

4. Klamroth-Marganska, V., Blanco, J., Campen, K., Curt, A., Dietz, V., Ettlin, T., Felder, M., Fellinghauer, B., Guidali, M., Kollmar, A., Luft, A., Nef, T., Schuster-Amft, C., Stahel, W. and Riener, R. Three-dimensional, task-specific robot therapy of the arm after stroke: a multicentre, parallel-group randomised trial. Lancet Neurol, 13 (2). 159-166.

5. Krebs, H.I., Volpe, B.T., Williams, D., Celestino, J., Charles, S.K., Lynch, D. and Hogan, N. Robot-aided neurorehabilitation: A robot for wrist rehabilitation. Ieee Transactions on Neural Systems and Rehabilitation Engineering, 15 (3). 327-335.

6. Martinez, J.A., Ng, P., Lu, S., Campagna, M.S. and Celik, O. Design of Wrist Gimbal: A forearm and wrist exoskeleton for stroke rehabilitation IEEE Int Conf Rehabil Robot, 2013. 1-6.

7. Masia, L., Krebs, H.I., Cappa, P. and Hogan, N. Design and characterization of hand module for whole-arm rehabilitation following stroke. Ieee-Asme Transactions on Mechatronics, 12 (4). 399-407.

8. Nijenhuis, S.M., Prange, G.B., Schäfer, J., Rietman, J.S. and Buurke, J.H. Feasibility of a personalized arm/hand training system for use at home after stroke: results so far International NeuroRehabilitation Symposium (INRS), Zürich, Switzerland, 2013.

9. Pehlivan, A.U., Rose, C. and O'Malley, M.K. System characterization of RiceWrist-S: A forearm-wrist exoskeleton for upper extremity rehabilitation. IEEE Int Conf Rehabil Robot, 2013. 1-6.

10. Reinkensmeyer, D.J., Wolbrecht, E.T., Chan, V., Chou, C., Cramer, S.C. and Bobrow, J.E. Comparison of threedimensional, assist-as-needed robotic arm/hand movement training provided with Pneu-WREX to conventional tabletop therapy after chronic stroke. Am J Phys Med Rehabil, 91 (11 Suppl 3). S232-241.

11. Rossini, P.M., Calautti, C., Pauri, F. and Baron, J.C. Post-stroke plastic reorganisation in the adult brain. Lancet Neurology, 2 (8). 493-502.

12. Schabowsky, C.N., Godfrey, S.B., Holley, R.J. and Lum, P.S. Development and pilot testing of HEXORR: Hand EXOskeleton Rehabilitation Robot. Journal of Neuroengineering and Rehabilitation, 7. 